\title{
Media responsibility and accountability: New conceptualizations and practices
}

\author{
JO BARDOEL and LEEN D'HAENENS
}

\begin{abstract}
This article will provide an overview of recent conceptualizations of media responsibility and accountability, and related concepts such as governance. Furthermore, new arrangements for media governance will be looked at in line with the four accountability mechanisms proposed in this article: political, market, professional and public accountability. Finally, some interesting media accountability practices to be found throughout Western Europe and across the Atlantic will be presented.
\end{abstract}

Keywords: media responsibility, media accountability, media governance, accountability mechanisms

\section{Introduction}

Nowadays, over fifty years after the introduction of the 'social responsibility theory' (Hutchins Commission, 1947), we witness a new increase in attention, including a new sense of urgency, for 'social responsibility' in the media. This is due to a number of reasons, the first being the recent structural media changes that are often characterized by catchphrases such as competition, commercialization and globalization. Second, as a result of the first, public provisions in the media sector, such as public broadcasting and responsible journalism, find themselves in a state of uncertainty, or even crisis. For public broadcasters in Europe, the recent liberalization of the broadcasting markets and the shifts in governance from a national to a European level constitute, to say the least, great challenges, both on an institutional level and in terms of legitimization. Informal arrangements to ensure the public interest in the media, like an independent professional culture, also seem to be challenged by an ever more business-oriented management culture and by more individualized production processes as a result of new technol- 
ogies. While in recent decades mass media in most European countries have experienced a considerable shift from the public domain to market mechanisms, the same media have acquired an ever more central position in the mediation of politics and culture.

\section{New conceptualization of media responsibility and accountability}

A single, coherent theory of the media's social responsibility simply does not exist, as relevant literature shows (BRU, 1985; McQuail, 1994). The concept of media responsibility is commonly used in relation to media content as well as to its function in society (Council of Europe, 1994; Siune and Hultén, 1998). Social responsibility of the media can be interpreted in terms of both 'responsibility,' referring to the media's responsibility with regards to society, and 'responsiveness,' relating to the manner in which the media listen to and take the public into consideration.

\section{The social responsibility theory}

Advocates of 'responsible' media usually originate from the media practice; when urgent problems arise, calls for reflection and action both from within and outside the media profession emerge. An early and important initiative in this respect came into existence after the Second World War. In the United States, the Hutchins Commission (1947: 126) formulated the so-called 'social responsibility theory of the press'. According to this Commission, media owners have an important role in society; "An overall social responsibility for the quality of press service to the citizen cannot be escaped; the community cannot wholly delegate to any other agency the ultimate responsibility for a function in which its own existence as a free society may be at stake".

The commission saw the press both as a commercial product and a 'public trustee'. In the 1940s this was a quite daring vision, since the traditional combination of the freedom of the press and market freedom had always been the firm basis for non-interference in the press sector. Nevertheless, these conclusions would strike a sympathetic chord in the United States and Europe in the decades to come, since they formed a counterbalance against the commerce and partisanship that had been allowed to develop.

The concept of the media's 'social responsibility' shows remarkable similarities to the German concept of 'Öffentlichkeit' ['public sphere'] that took shape in the 1960s, to become popular again in academic circles during the 1990s. One striking difference is that the main exponent of this theory, Jürgen Habermas (1989; 1996), placed more emphasis on 
the community's so-called 'communicative competence,' in contrast to the more individualistic approach that appeared in the Anglo-American system.

\section{Social responsibility in practice}

Apart from these theoretical notions, McQuail (2000) favors a practical description of the concept of media responsibility, and defines it as the 'obligations and expectations' that society has regarding the media. He distinguishes between four types of responsibility: assigned, contracted, self-assigned and denied responsibilities. 'Assigned responsibilities' are obligations established by law, which the media must meet. In democratic societies this regulation, in pursuance of the above-mentioned tradition of the freedom of expression, is kept to a minimum. 'Contracted responsibilities' arise from self-regulated agreements between the press or broadcasters on the one hand and society or politicians on the other in regard to the desired conduct of the media (for example the showing of violent images on television). 'Self-assigned responsibilities' indicate voluntary professional commitments to maintaining ethical standards and public goals. Finally, he refers to 'denied responsibilities' in order to refute accusations of irresponsibility that are thought to be undeserved or inapplicable.

Hodges (1986: 14) makes an important distinction between 'responsibility' and 'accountability.' In his definition, responsibility refers to the question: 'What social needs should we expect media and journalists to respond to?' Accountability offers an answer to the question: 'How might society call on media and journalists to account for their fulfillment of the responsibility given to them?' Responsibility thus has to do with defining proper conduct; accountability with compelling it. Pritchard (2000: 2) defines media accountability as "the process by which media organizations may be expected or obliged to render an account of their activities to their constituents". He thus stresses that media accountability is a 'process' that basically consist of "naming, blaming and claiming" (2000: 3).

McQuail, in his newest book (2003: 195), indicates that the term social responsibility not only has different meanings, but also implies "differences of location of a given responsibility within the whole institutional complex". Media responsibility can thus be located on different levels; the media institution as a whole, the ownership, the organization and its management, the professional employee and the individual author or performer.

In the last decade, we have seen a clear shift amongst communications specialists from more general and abstract thinking about media respon- 
sibility to a more practical and concrete interpretation of these concepts (from responsibility to accountability), in which the emphasis has furthermore shifted from a negative approach to a positive one, from liability to answerability. The liability model of accountability is, according to McQuail (2003: 204) "mainly invoked in cases where the media are believed to be capable of causing real harm to individuals, certain categories of people or society as a whole". Answerability on the other hand implies "responsiveness to the views of all with a legitimate interest in what is published, whether as individuals affected or on behalf of the society. It includes a willingness to explain, defend, and justify actions (and general tendencies) of publication or omission" (204). At the same time, it must be said that new conceptualizations of media responsibility and accountability primarily come from within academic and policymaking circles, and that the debate has so far reached media professionals only recently and to a limited extent.

\section{Governance}

In addition to the discussion on the social responsibility of the media, in the last ten years of the $20^{\text {th }}$ century, the term 'governance' emerged out of the blue, all of a sudden taking a central position in policy debates. People in the field and political scientists consider the concept of 'governance' as a new way of evaluating the government and the relationships between the government and society. In its report 'Governance in the Public Sector: A Governing Body Perspective' (2001), the IFAC Public Sector Committee sketches the outlines of 'good governance' in the public sector. In doing so, the IFAC distinguishes four levels at which 'good governance' (or lack thereof) can be assessed: 1) 'standards of behavior' (referring to leadership and values such as objectivity, integrity and honesty);2) organizational structures and processes (referring to communication with shareholders and the relationship between management and personnel, among others); 3) existing control mechanisms (such as risk management, internal audits and personnel training), and 4) external reporting (annual reports, external audits, performance criteria). In the European Union much attention is given to what is called 'multi-level governance, as an indicator of the shared responsibility of and continuous negotiations between all the policy levels involved: local, regional, national and supranational. From an overview of the relevant literature, Van Kersbergen and van Waarden (2001) conclude that the concept of governance implies, among other things, a pluri-centric approach, an emphasis on processes and functions against the structure of - in their case - governments, and predominantly normative notions. 
This new emphasis on (good) governance, which stems from a more practical, policy- and management-oriented discourse, also points in the direction discussed above; organizations and institutions are no longer judged solely on their good intentions, but primarily on demonstrable and, if possible, measurable performance criteria.

\section{Four accountability frames}

There are many different reasons why the concept of social responsibility of the media has gained new relevance. In putting social responsibility into practice there are different procedures, frames or mechanisms to hold media accountable for their performance vis-à-vis society. Lange and Woldt (1995) state that the realization of social responsibility of television results from the interplay between several factors: constitution and law; supervision and control (licensing, et cetera); condition of the television market, journalistic responsibility and self-regulation. Bertrand (2003: 11) indicates that there are three approaches to improve the quality of the media: 1) the law and courts; 2) the market, and 3) media ethics and accountability systems. McQuail (2000) defines four accountability frames: law and regulation; the market; public, and professional responsibility. Along the same lines, Bardoel (2000; 2001) slightly 'remolds' that typology into the following four media accountability mechanisms: (1) political accountability, which refers to formal regulation stipulating how broadcasting companies and newspapers will be structured and how they function; (2) market accountability or the system of supply and demand, in which the free choices of the public are given free reign and considerations of efficiency also play a role; (3) public accountability, which is linked to the media's assignment of maintaining more direct relationships with citizens, in addition to their relationship with the market and the state; and (4) professional accountability, which is linked to ethical codes and performance standards used within the media that should help counterbalancing every excessive dependence upon politics and the market.

In the next section we will look into relevant trends in the respective, above-mentioned media accountability mechanisms. Within the framework of political accountability we will focus on the position of public service broadcasting in the light of recent European policy-making.

\section{New arrangements for media governance beyond the market and the state}

Towards multi-level governance

There seems to be a growing consensus that increasing 'power' or, better, 'influence' of the media has to be counterbalanced by greater media 
transparency and accountability. However, there is no consensus on how the latter should be achieved. Governments are often considered as the classic guarantee for a sound media system, but they have proven to be quite ineffective in preventing media monopolies in the press or broadcasting industries and in stimulating the plurality of media content. They experience also problems with the organization of public broadcasting 'at arms length'. More in general, media regulation proves to be rather ineffective in the management of content. In recent decades, media markets were seen as a new panacea for the problems of public and/or government-controlled media: inefficiency, inflexibility and bureaucratization, paternalism and lack of interest for popular taste and culture, lack of innovation, and so forth. More recently, the dark side of marketdriven media is getting more attention; its mainstream orientation, its interest in consumers (not citizens), the influence of advertisers and sponsors, et cetera.

The trend of 'less government' and 'more market' also sheds new light on the position of the media professionals; they have become the 'guardians' of the quality of media output, while at the same time the public spirit of and the public space for professional journalists and other creative people tend to diminish. Media professionals want to work 'for the people,' but often see accountability to the public and to society as no less threatening than the forces of the market or the state. More than ever in the past, the citizen is becoming an active part of the (mass) communication process, due to the potential of new technologies, more competition between media and, last but not least, a more self-conscious and better educated citizenry. Involvement of citizens and civil society can also provide a 'fourth' way to organize social responsibility in the media, next to the primacy of either the market, the state and/or the professional. There is, in other words, a growing awareness that an adequate media and communications 'ecology' can best be organized, not by exclusively relying on one of these parties or mechanisms, but by way of interrelated and multileveled 'governance' arrangements in the media system. This also corresponds with new approaches in the reflection on public policies and business strategies. In the next section an overview of relevant trends in accountability practices will be given and some conclusions will be drawn.

\section{Whose political accountability?}

Political accountability was - and in fact still is - dominant in public broadcasting, the single most prominent provision to foster the public interest in the media. This system includes the legal framework for regulating the structure and functioning of broadcasting through national 
political and administrative institutions. However, as of 1989, European policy-making has taken over the primacy from national politics when it comes to broadcasting e. g., European content; although national regulation continues to be the most extensive, the latter has to remain within the framework of the European legislation. Generally this shift in governance is felt as threatening for public broadcasting, since a European economic and 'open market' approach overrules national cultural policies.

In a recent article, David Ward (2003) considers the often-heard criticism of the merely economic, industry political approach of the European Commission as one of the causes of the decline of the public service model in the broadcast sector, as fully unjust. Ward sees consistent reasoning in the Commission's approach; recognition of the public service as a cornerstone of democracy, as a service of general economic interest, essential to improve the quality of life of all citizens and to conquer social exclusion and isolation, as adopted in a Protocol to the Amsterdam Treaty on public service broadcasting (known as the Amsterdam Protocol) in 1997. It is then up to the member states to define the mission statement of the public service (in terms of delivering geographical universal service and through thematic channels as ancillary services aimed at niche audiences) and to choose appropriate financing solutions (including the principle of mixed financing). The Commission sees its competence limited to questions whether the chosen financing method is adequate and proportionate to the task imposed, and how state aid is being used or misused in competing, secondary markets such as publicity. A Communication on the application of state aid rules to public service broadcasting was published (European Commission, 2001), but an effort to clarify the EU's stance on PSB was rejected by member states, which leaves the Commission to adopt an 'ad hoc' approach. The real danger is then that the primary role of the nation state in the future of the public service is lost altogether.

Meanwhile, a new communication on services of general interest (European Commission, 2001) and the amended 'Transparency Directive' (European Commission, 2000b) were adopted. Both clarify questions related to the financing of services of general economic interest, among which PSB. These improvements made possible in the Transparency Directive aim at discerning between public service and commercial activities of a public service; transparency needs to be made visible in a clear-cut separation - including separate book-keeping - between the public and non-public activities of the public service. It seems very unlikely that the Commission is going to follow the Directorate of Information, Communication, Culture and Audiovisual Media in wanting to make a program-based distinction between public and commercial 
broadcasting. One of the reasons being the difficulty of defining public service by means of a mere set of essential institutional and contentrelated characteristics, inspired by normative notions of quality. Article 86(2) has proven very useful and flexible enough to enshrine a wide variety of public service models.

\section{Public service broadcasting models}

Karol Jakubowicz (2003) presents an inventory of the different public service models that are at stake in the European debate. This range is undoubtedly broad; from the so-called 'attrition model' where the PSB broadcasters are not allowed to adopt digital technology nor to develop new channels or services, all that being reserved for commercial broadcasters, over the so-called 'full portfolio model' with universal and specialized broadcast, digital and online services, to the so-called 'personalized public service,' operating in an on-demand environment, as providers of individual public service content.

The public broadcasting service will be assessed according to its power to discriminate its programs from those of the commercial sector, its internal pluralism, its contribution to a production climate, which gives room to innovation. In her search for workable alternatives for the public broadcast service to keep its distinctiveness, Jeanette Steemers (2003: 133-4) warns for the hybridization between public and private broadcasters carrying both the benefits and the disadvantages of each model:

"Moreover, with the current difficulties faced by commercial television, the questioning of public service broadcasting's 'distinctive' role is quite likely to increase. At the same time, greater thought needs to be given to alternative and complementary forms of public provision which may be better suited at meeting changes in communications needs, content, and delivery forms than the large-scale, public institutions framework."

It is up to the member states and the broadcasting services themselves to come to the Commission with a commitment to the principles of the public service and with an exact declaration of what those principles are. Ironically enough, it proves all but easy to define the current and future role of PSB in the audiovisual landscape of the nation states. Jakubowicz (2003: 157) describes this problematic two-tier accountability system as follows:

"PSB organizations in EU member states are accountable to public authorities, and the member states themselves are accountable to the 
European Commission for the way they confer, define, organize and finance the public service remit, as well as institute and operate program and financial accountability systems for PSB broadcasters. That would seem to offer hope that an accountability system could be developed on this basis, providing clear criteria at least as to what constitutes the public service remit of PSB broadcasters in EU countries and how to distinguish it from other programming".

As said, this is unfortunately not the case, given that the various bodies of the European Union have not come much further in defining PSB than what had already resulted in the Prague Declaration, signed at the fourth Minister Conference of the Council of Europe in 1994. This resolution dealt with four main aspects of public service: the responsibility of public services in terms of information diffusion; financial requirements; political independence and the duty to public accountability; access to new technologies.

All in all, it is recognized that PSB is directly related to democratic, social and cultural needs seeking to reach a wide audience, willing to invest in innovation. Jakubowicz (2003) pleads in favor of a rigorous accountability system that would encompass questions such as accounting for what, to whom, and how. Ingredients for measuring performance would certainly need to include, alongside mission statements, financial accountability on the basis of economic performance measures, audience performance based upon audience shares and reach.

Notwithstanding, numerous problems remain; due to convergence of broadcasting and telecommunication, and the switch from analog to digital communication it has become all the more difficult to define the concept of public service. The decision to create separate regimes for transportation and content calls for the question how to keep these sectors separate. Public broadcasters will want to make use of new communication technologies and after digitization lies the possibility of broadband transmission. In Europe no standard has been chosen yet, therefore penetration is still minimal. Hence public broadcasters set up interactive websites as the easiest solution to keep in touch with their audiences. Protests from the commercial sector against this new strand of activity were vehement. The European Commission rejected the claim that this should be considered as misuse of state aid, arguing that services which are not programs in the traditional sense of the term, such as online information services, can nevertheless be considered as an integral part of the broadcast mission in the digital age, since they intend to fulfill the same democratic, social and cultural needs (Porter, 2002).

In conclusion we notice that, whatever the outcome of these policy debates will be, national public broadcasters will increasingly be con- 
fronted with new kinds of multi-level governance and accountability. The European Union demands a clear-cut definition of the mission of public broadcasters and also a clear distinction between public and commercial broadcasting services. This means that the days that national broadcasting policy formation took shape as a strategic ritual between intimate partners are gone, and that more open and transparent relations between regulators and broadcasters will need to emerge. In fact, more explicit legitimization in terms of social responsibility and concrete accountability mechanisms has already become a strategic asset for public broadcasters over the last ten years, as Bardoel and Brants (2003) explain for the Dutch case. Next to this more explicit political accountability towards national and European governments, public broadcasters also try to organize more direct interaction and feedback with the public, as will be illustrated later in this article.

\section{Market accountability}

"The objective of the marketplace model", Merrill (1989: 12) writes, "is to permit the maximum of individual and independent editorial determinism in what ideally will be a very pluralistic market system. Media that people accept and support will survive and thrive; media that people dislike or reject will suffer and die. This is ultimate accountability. And it is the kind of accountability in harmony with the spirit of individualism, democracy, and freedom."

Market accountability is, especially in a European context, only rarely considered an adequate, let alone ideal mechanism of social responsibility. Yet the market undoubtedly is the oldest vehicle for freedom of expression and communication in society. Although it seems at present quite uncommon to associate the market mechanism with communication freedom, in past centuries it has proven to be a liberating power against the vested interests of the church and the state. Also in the present day, the system of demand, supply and competition offers a good, simple and unprejudiced indication of consumer tastes, and the market mechanism does not involve compulsion. Phenomena like pop music and other forms of popular culture would never have penetrated our culture so rapidly without the freedom of the market. At the same time, this model tends to favor majority preferences over quality of content or critical and minority voices. For public broadcasters this model may function as a useful antidote against the traditional 'supply side' paternalism and as a stimulus towards more efficient behavior and the recent development of a quasi 'internal market' (cf. BBC's 'producer's choice'). For them this mechanism is especially relevant to the extent that advertising is a substantial source of income; thus 'market shares,' or in fact 
'audience shares,' become an important parameter. In such a context, marketability may be confused with accountability.

Nevertheless, in relation to market accountability we do not, in the first place, think of broadcasting, but of traditionally commercial media sectors such as the press and of newly developed private media practices in the field of commercial broadcasting and new media such as the Internet.

The press sector has always been based upon a delicate combination of private enterprise and public responsibility. Most newspapers originally emerged from political and civil movements, but in the meantime they have merged into a small number of media conglomerates with a decreasing number of titles and the concentration of various editorial tasks. Because of similar trends in most countries, the traditional position of the daily press in the Western world as the mouthpiece of societal groups and political movements and as the breeding ground for independent journalism has become ever more vulnerable.

In The Netherlands and elsewhere, the press sector (Bardoel and d'Haenens, 2003; forthcoming) has always known a strong, liberal tradition of press freedom, which is by definition very reluctant towards the notions of social responsibility, especially in combination with concrete accountability mechanisms. As a result press policy has always been based on self-regulation by the sector, and only very limited government intervention took place. This tradition is in sharp contrast to policy practices in the broadcasting sector, which is characterized by a tradition of strong public intervention. Given the recent structural changes in the press sector, it is not clear whether the informal provisions that supposedly counterbalance the commercial logic of these media, such as the professional freedom of journalists and the public spirit of 'responsible' media entrepreneurs, will hold. Also more formal provisions such as the 'editorial statute,' are often too weak to make a real difference. Even in the United States, journalists place accountability first and foremost in their own newspapers, and "there has been no real acceptance of the marketplace approach to accountability by American journalists thinking about it in the context of ethics," Merrill (1989: 18) concludes, referring to a nationwide study carried out back in 1973 .

Commercial broadcasters appeared on the scene only very recently in most European countries, and they initially positioned themselves as being so different from the traditional public broadcasters that 'social responsibility' notions were not 'top of mind' thus far. Not surprisingly, Bardoel and Brants (2003) conclude that notions of responsibility and accountability are still an almost unknown phenomenon within commercial broadcasting, as the Dutch case shows. Commercial broadcasters want to please their advertisers and shareholders first and foremost, but 
also prefer to avoid problems with politics that would trigger further regulation. Commercial broadcasters in the Netherlands only seldomly refer, neither in formal policy documents nor in public utterances, to their responsibility to the public at large or society. Nonetheless, there are signs, as stated by Bardoel and Brants (2003) that commercial stations are also beginning to deal with this issue. They suppose that this might have to do with the commercial broadcasters wish to challenge the public broadcasters exclusive claim on public privileges and funding and their accusations of unfair competition. In terms of the 'liability' or 'answerability' model of accountability proposed by McQuail (2003), commercial broadcasters still seem to prefer a quite defensive 'liability' model. Active accountability by engaging in a dialogue with critics in society has only recently begun to develop. The number of assigned responsibilities, imposed by society and the law, remains, in both the Dutch and European regulation, rather poor (Machet, Pertzinidou, and Ward, 2002). Contracted responsibilities, such as voluntary promises to the audience, are almost absent. Relatively extensive are the self-assigned responsibilities in order to guarantee a professional and independent information provision by editorial statutes (although imposed by Dutch law) and codes of conduct, but little is known about its implications. At the same time some commercial broadcasters still deny their social responsibility, by referring to the 'realistic' nature of their programming or, ultimately, by pointing at freedom of the viewer to switch the program.

\section{Professional accountability}

The professional accountability frame does relate less to the 'vertical' and formal structuring of media organizations and more to the "horizontal' and often informal identification of media professionals with the standards of their own profession. Professional responsibility refers to the performance criteria and ethical codes of media professionals that are often supposed to complement to, or better, compensate for the political or market dependency of media organizations. The development of professional responsibility and indeed of professionalization of media occupations has in past decades often been seen as a progressive force $v i s-\grave{a}$-vis the traditional influences of the political or the market system. According to McQuail (2000: 187) this professional framework is likely to work because it is voluntary, self-regulatory, non-coercive and in the self-interest of media and professionals. But it has in his view also serious limitations, since professionalism is in most cases not strongly developed within the media and as a result media professionals have relatively little autonomy from media management and ownership. 
Media professionals in The Netherlands have steadily improved their position within media organizations over the last forty years, thanks to a better professional training and strong negotiations that have led to professional privileges as 'editorial statutes' in every newspaper and broadcasting organization. At the same time it remains to be seen if this collective, informal professional culture and its privileges will survive the current processes of commercialization and globalization. Practice has shown, however, that editorial statutes only seldom protect newsrooms against press concentration and media mergers.

The press sector has, given its well-known aversion against externally imposed regulation and codes of conduct, always relied on mechanisms of internal criticism and self-regulation. In the past, Dutch newspapers that originated from a political or social movement could count on the loyalty and commitment of citizens who belonged to the same movement. These classical forms of participation have eroded though, and are replaced by a (quasi) commercial, consumerist relationship. As a result, the relation of newspapers with their respective readerships has become looser, and since most newspapers have recently lost circulation, some of them have tried to revitalize the relationship with the reader. This results in new initiatives such as reader's pages, ombudsmen and so on. More recently, there is much more debate and introspection within the journalistic profession itself. This debate was triggered by external criticism on reporting on issues such as the Scebrenica massacre and the murder of Pim Fortuyn. Media were accused of being partly 'guilty' in these cases, since most media unanimously took position in favor of a Dutch military intervention in Bosnia or against the populist politician Fortuyn. Elsewhere in Europe there were similar debates on the role of the press in relation to the rise of right-wing extremism. The media and media professionals were also accused of operating too close to the inner circle of vested politics and culture, which are recruited from the same social middle class as most journalists, and too distant from the problems and needs of ordinary citizens.

Concentrating on the journalistic position in light of the Internet, we notice that publishers, broadcasters and Internet service providers (ISP's) each provide about 30 percent of the almost 200 news sites currently available in The Netherlands. Most of the news supplied on the Internet still is of a 'parasitic' kind, usually referred to as 'shovelware'. Internet journalism finds itself still close to traditional formats of news distribution, as recent research showed time and again (Bardoel and Deuze, 2001). Within the terms of this modest practice, it is not surprising that - according to research findings - newspaper sites prove to be better in using the interactive potential of the Internet, such as discussion groups, feedback via e-mail and access to archives. Television news sites 
on the other hand make a better use of the multimedia features of the Internet and also offer more hyperlinks (Jankowski and van Selm, 2000). Internet journalism is thus a mere affiliate of its big brothers, and the potential of the new medium is often not fully used in order to avoid cannibalization of the traditional medium. Given the high potential but still poor performance of the Internet as a journalistic medium (see d'Haenens, Jankowski, and Heuvelman, forthcoming) and the lack of research and development in this respect by newspaper publishers, The Netherlands Press Fund has decided to fund research on and offer financial support for journalistic content production on the Internet.

\section{Public accountability}

Finally, public accountability has gained considerable popularity over the last decade. Although the concept and the very name of 'public broadcasting' already suggest a strong emphasis on public responsibility, the reality was and is that public broadcasters rely heavily on their (exclusive) relationship with politics. In trying to define 'public responsibility,' McQuail (2003: 233) indicates that the general idea behind this is that the media ought to serve public purposes and be socially responsible; the theory of social responsibility of the media and the idea of media as a 'public trustee' are relevant here again. These ideas find both support, according to McQuail, from within the media that choose an active role in society and wish to contribute to the public good and, outside the media, with individuals and groups as constituents of civil society and operating in the public sphere. All things considered, these many voluntary action groups are part of the informal 'mechanisms' by which media are constrained to meet certain standards of performance in society. Alongside these feedback mechanisms with informal but still collectively organized institutions, the relationship with the audience also becomes an ever more important part of public responsibility. Already conscious citizens hold the media accountable for their performance through a process of naming, blaming and claiming (Pritchard, 2000). With individualization being a formidable social trend, public broadcasters can no longer rely on their relationship with formal and informal groups and collectivities; they have to establish a relationship with the individual, 'unorganized' public (Brants, 2003). The problem with this kind of accountability procedures is, however, that they are voluntary most of the time; it is often hard to see the difference between real feedback procedures and ritual PR strategies.

The increasing consideration for the citizen's position is also noticeable from the growing support for 'public' or 'civic' journalism wanting to focus on, instead of political or media priorities, the 'agenda of the citi- 
zen' and trying to stimulate public discourse and civic participation. Some academics point out the fact that the relationship between citizens and media has changed considerably, and as a result want to do away with the classical distinction between politics, journalism and the public sphere on the one hand and popular culture, entertainment and the private sphere on the other. This implies that, looking at responsibility and accountability of the media, we should not exclusively refer to the institutional aspects and traditional forms of participation, but instead also include the actual media use of citizens (entertainment and hybrid formats - 'infotainment' - having acquired a prominent status in their daily media menus).

\section{Media accountability practices}

The academic debate will now be left behind and the current state of the art of concrete appearances of professional accountability mechanisms in the press and broadcasting practices will be looked into. In sharp contrast with the traditional, somewhat stubborn journalistic attitude grounded in a 'common sense' approach (in the sense of "We know what news is!"), a new, cautious attitude seems to emerge among media professionals who do want to be held accountable for the ways in which they shape their responsibility, based upon verifiable criteria, such as a transparent editorial statute and an internal professional codex.

To what extent media ethics indeed do offer solace remains questionable. Traditionally, relations between journalism and ethics are somewhat strained; journalism pretends to register, to report facts, while ethics refer to so-called 'preferred visions'. Moreover, ethics-related issues predominantly tend to get the attention in times of crisis reporting only. In a lot of countries in the Western world, discussions on media ethics have become fashionable, but this does not mean, however, that some concrete initiatives have not yet been taken. For years, so-called Media Accountability Systems (cf. Bertrand, 2003) were settled as undesirable, imposed shackles that would constitute impediments for journalistic freedom, even human rights and the exercise of democracy. The following paragraphs will assess a number of concrete appearances of accountability mechanisms that can be considered best practices in different geographical contexts. What are the main characteristics of these accountability mechanisms?

According to Blumler and Hoffmann-Riem (1992), a public accountability system is to be seen as a set of interconnecting elements, of which the main ingredients should be: (1) enhancing the involvement of media professionals in organizational policy-making; (2) greater interplay between social scientific researchers and media makers; (3) greater involve- 
ment of social groups in debates of broadcasting policy; (4) greater involvement of, and attention to, radio and television criticisms in the media; (5) greater role for citizens' organizations in broadcasting accountability in order not to limit the discourse among the 'elite' alone; (6) periodic appointment of bodies at the national and regional levels in an effort to 'stuff' the broadcasting policy debate with all these different strands of opinion. Jakubowicz (2003: 152) realistically remarks that unfortunately not much has survived from these idealistic proposals, since “(...) 'upward' lines of largely formalized accountability (reports, audits, execution of license obligations, etc.) continue to prevail".

In an attempt to grasp the variety of concrete accountability mechanisms ${ }^{1}$, both internal and external, according to the above-mentioned political, professional, and public 'frames' of media accountability (the market rarely being an adequate mechanism of social responsibility), a contract between the government and the public broadcaster refers to the political accountability frame. Such a contract sets out some sort of legal framework for regulating the functioning of broadcasting. Examples of a formal contract between the government and broadcasting are, among others: the Royal Charter in the United Kingdom, the Broadcasting Concession Act in The Netherlands, and the management agreement between the Flemish public broadcaster, the VRT (a public limited company), and the Flemish Government (its chair holder). The latter merits closer attention: emphasis is placed upon the transparency of the agreements made between both contracting parties and upon the autonomy that is granted to the broadcaster during a determined period of time (five years). The 'management agreement' stipulates that the VRT must attract the greatest possible number of viewers and listeners by offering a diverse selection of programs that excite and fulfill their interests. Conditions for the management contract to work are, among others: a solid, legal basis; stable financing; a good definition of output; preferably a long-term contract; a relationship based upon mutual trust; necessary monitoring tools. A combination of external formal regulation through a supervisory body and some kind of internal, self-regulatory mechanism is the British new Office of Communications (Ofcom), operational as of December 29, 2003, which merged the functions of five formerly existing regulatory bodies: the Independent Television Commission (RTC), the Broadcasting Standards Commission (BSC), the Office of Telecommunications (Oftel), the Radio Authority (RAu) and the Radiocommunications Agency (RA) in an effort to regulate the full realm of the electronic communications sector.

The professional accountability frame refers to identification of media practitioners with the standards of their own profession. By way of an example, and in light of the legislation on government openness, we refer 
to the VRT that, like all Flemish public organizations, has an ombudsman to whom the public can address themselves if they should find that insufficient openness is offered. In Sweden, a press ombudsman also supervises the correct implementation of the rules on the integrity of journalists, the origins of news sources, etc. The Swiss Ombudsstelle may be seen as a variant of the Swedish ombudsman and has the authority to operate outside the media organization as well as within it. Also in the United Kingdom, national newspapers have appointed ombudsmen, but few of them are still active now. CBC/Radio Canada has an ombudsman with authority over all information programs offered by public broadcasting (radio, television and Internet). Appointed for five years, the ombudsman operates entirely independently of CBC staff, reports directly to the chairperson of the $\mathrm{CBC}$ about complaints regarding lack of accuracy, balance or integrity in the reporting.

Another example of internal accountability mechanisms are forms of self-regulation within the media organization, such as the Deutscher Presserat in Germany. Readers may address themselves directly to this Presserat without having to go through an intermediary. The impact of this form of self-regulation is limited, however. A similar self-regulation instrument, the Deutscher Werberat, exists for advertising. This council is composed entirely of professionals from the advertising world, but it is not known for having a consistently critical attitude with respect to its own professional practice. The BBC's Producer Guidelines act as a code of professional conduct and the broadcaster also has a so-called Programme Complaints Unit to which the public can address their criticisms and complaints. The newspaper and magazine sector created a Press Complaints Commission (PCC): there is a professional code, complaints are heard and conclusions are published.

The fact that the media are supposed to serve public interests is being put to the test through forms of public consultation. Canada offers an interesting public accountability model in which citizens - in all their geographic and ethnic diversity - are actively involved in the evaluation and possible steering of the concrete expression of public responsibility by the media. One example of public consultation is the so-called Public Hearings that the CRTC (Canadian Radio-Television Telecommunications Commission) regularly organizes. These are fora on the 'Public Accountability' of both public and commercial broadcasters throughout the country, including in remote areas. These public consultations take place whenever a broadcasting license is up for renewal or when the CRTC wants to collect information about new policy directions or licensing decisions. These consultations, in the form of semi-structured interviews, are broad; anyone can participate, including industry representatives, organized public interest groups or ordinary members of the public. 


\section{Jo Bardoel and Leen d'Haenens}

The process of such forums has been archived as audiovisual material and can be consulted through the Internet. One of these forums - e.g., Deciding What's News (Vancouver, September 30, 2001) - deals with convergence of media conglomerates and its impact on the news user, and tries to find an answer to the question how the Canadian audience can continue to consider the public broadcasting service as the most credible news source. The Inuit and Indian peoples are not left aside, as is illustrated in the so-called 'First Nations Accountability Coalition.' Transparency and openness of government policy towards citizens in each and every area are considered paramount in Canada, as is testified in the Access to Information Act, which stipulates that everyone who pays $\$ 5$ within thirty days should be provided with the necessary clarifications on every government decision (with the exception of national security files, decisions related to the private realm, etc.).

\section{Conclusion}

Structural changes in the media landscape, such as increased competition and commercialization, have meant that the topicality and urgency of the question of the 'social responsibility' of the media is growing. This can be seen in the recent academic interest in the concept, as well as the attempts to define it and the reflection on its possible concrete expression. Analogous to this, the discussion on the social responsibility of companies and organizations seems to also have become a central point of concern within the business community and the government, resulting in new terms such as 'corporate governance' and 'accountability'. The recent bookkeeping scandals surrounding Enron and Parmalat have shown the urgent need for formulating 'corporate' responsibility criteria once again.

A concrete expression of social responsibility offers the advantage that it makes possible a shift from the level of the media professional's individual, ethical reflection to the collective interpretation of social responsibility at the level of the media organization. Given the structural changes in the media context - such as commercialization, increasing competition, decreasing public spirit and more self-conscious and demanding citizens - a shift in media ethics and accountability systems from the level of the individual professional to media organizations and institutions seems imperative. A review of the existing literature on the subject shows us that there is a growing interest, but not yet a coherent framework on the subject, apart from definitions and categorizations of mechanisms for social responsibility (such as internal versus external, and a 
division into political, professional, public and market accountability). Also, the concrete media practice shows a plethora of internal and external accountability mechanisms. In all, we conclude that the press has done more in terms of looking for internal accountability mechanisms than the broadcasting sector, where the public broadcasters have more experience with assigned (by the government) and external accountability mechanisms than their commercial counterparts (e.g., visitation commission in The Netherlands; Bardoel, 2003).

\section{Note}

1. The article section providing a presentation of concrete accountability mechanisms is a concise version of parts of an article that will be published in a forthcoming issue of the European Journal of Communication (Bardoel and d'Haenens, forthcoming).

\section{References}

Bardoel, J. and d'Haenens, L. (2003). Media en maatschappelijke verantwoordelijkheid; van theorie naar praktijk [Media and social responsibility; from theory to practice]. In Raad voor Maatschappelijke Ontwikkeling (RMO) (2003). Medialogica. Over het krachtenveld tussen burgers, media en politiek. Advies 26, januari 2003 [Media Logic. About the dynamic relationship between citizens, media and politics. Advice 26] (pp. 99-151). The Hague: Raad voor Maatschappelijke Ontwikkeling / Sdu Uitgevers.

Bardoel, J. and d'Haenens, L. (forthcoming). Media meet the citizen: Beyond market mechanisms and government regulation. European Journal of Communication, 19(2).

Bardoel, J. and Brants, K. (2003). From ritual to reality. Public broadcasters and social responsibility in the Netherlands. In G. F. Lowe and T. Hujanen (Eds.), Broadcasting and Convergence: New Articulations of the Public Service Remit (pp. 167-187). Göteborg: NORDICOM.

Bardoel, J. (2003). Assessing public broadcasting in the Netherlands. Javnost / The Public, 10(3), 81-96.

Bardoel, J. (2001). Open media, open society. The rise and fall of the Dutch broadcast model: A case study. In Y. N. Zassourski and E. Vartanova (Eds.), Media for the open society (pp. 98-121). Moscow: Faculty of Journalism / Publisher IKAR.

Bardoel, J. and Deuze, M. (2001). 'Network journalism': Converging competencies of old and new media professionals. Australian Journalism Review, 23(2), 91-105.

Bardoel, J. (2000). Responsibility beyond rhetoric. Public broadcasters between citizens and the state. Amsterdam: University of Amsterdam.

Bardoel, J., Brants, K., and Plug, J. (2000). Responsible and accountable; Broadcasting policy between public obligations and private needs. In J. van Cuilenburg and R. van der Wurff (Eds.), Media and open societies (pp. 80-106). Amsterdam: Het Spinhuis.

Bertrand, J.-Cl. (Ed.). (2003). An arsenal for democracy. Media accountability systems. Cresskill, NJ: Hampton Press.

Blumler, G. and Hoffmann-Riem, W. (1992). Toward renewed public accountability in broadcasting. In G. Blumler (Ed.), Television and the public interest. Vulnerable values in west European broadcasting (pp. 218-228). London: Sage. 


\section{$24 \quad$ Jo Bardoel and Leen d'Haenens}

Brants, K. (2003). Auditing public broadcasting performance: Its theory and practice. Javnost / The Public, 10(3), 5-12.

Broadcasting Research Unit (1985). The public service idea in British broadcasting. London: BRU.

Council of Europe (1994). The Media in a democratic society. Political declaration resolutions and statement. $4^{\text {th }}$ European Ministerial Conference on Mass Media Policy. Prague (December 7-8). Strasbourg: Council of Europe.

d'Haenens, L. Jankowski, N. W., and Heuvelman, A. (forthcoming). News in online and print newspapers: Differences in reader consumption and recall. New Media and Society.

European Commission (2000a). Communication from the commission - Services of general interest in Europe (COM/2000/0580 final). Brussels: The European Union.

European Commission (2000b). Commission Directive 2000/52/EC of 26 July 2000 amending Directive 80/723/EEC on the transparency of financial relations between Member States and public undertakings. Official Journal of the European Communities, 29. 7. 2000.

European Commission (2001). Communication from the Commission on the application of state aid rules to public service broadcasting. Official Journal of the European Communities, 15. 11: 5-11.

Habermas, J. (1989). The structural transformation of the public sphere: An inquiry into a category of bourgeois society. Cambridge, MA: MIT Press.

Habermas, J. (1996). Moral consciousness and communicative action. Cambridge, MA: MIT Press.

Hodges, L. W. (1986). 'Defining press responsibility': A functional approach. In D Elliot (Ed.), Responsible Journalism (pp. 13-31). Beverly Hills, CA: Sage.

Hutchins Commission (1947). Report of the commission on the freedom of the press. A free and responsible press. Chicago, III: University of Chicago Press.

IFAC Public Sector Committee (2001). Governance in the public sector: A governing body perspective. International public sector study. New York: International Federation of Accountants.

Jankowski, N. W. and van Selm, M. (2000). Traditional news media online: An examination of added values, Communications, 25(1), 85-101.

Jakubowicz, K. (2003). Bringing public service broadcasting to account. In G. Ferrell Lowe and T. Hujanen (Eds.), Broadcasting and convergence: New articulations of the public service remit (pp. 147-165). Göteborg: Nordicom.

Lange, B. P. and Woldt, R. (1995). The results and main conclusions of the international comparison. In J. Dries and R. Woldt (Eds.), The role of public service broadcasting in the information society (pp. 463-503). Düsseldorf: European Institute for the Media.

Machet, E., Pertzinidou, E., and Ward, D. (2002). A comparative analysis of television programming in seven European countries: A benchmark study. Düsseldorf: European Institute for the Media.

Merrill, J. C. (1989). The marketplace: A court of first resort. In E. E. Dennis, D. M. Gillmor, and Th. L. Glasser (Eds.), Media freedom and accountability (pp. 1124). New York: Greenwood Press.

McQuail, D. (2003). Media accountability and freedom of publication. Oxford: Oxford University Press.

McQuail, D. (2000). McQuail's mass communication theory (4th ed.). London: Sage.

McQuail, D. (1992). Media performance. London: Sage.

Plaisance, P. (2000). The concept of media accountability reconsidered. Journal of Mass Media Ethics, 15(4), 257-268.

Porter, V. (2002). The global future of public service broadcasting. NHK Broadcast Studies, $1,1-20$ 
Pritchard, D. (2000). Holding the media accountable. Citizens, ethics and the law. Bloomington, IN: Indiana University Press.

Siune, K. and Hultén, O. (1998). Changes in broadcasting: Is public service still alive? In D. McQuail and K. Siune (Eds.), Media policy. Convergence, concentration and commerce (pp. 23-28). London: Sage / Euromedia Research Group.

Steemers, J. (2003). Public service broadcasting is not dead yet. In G. Ferrell Lowe and T. Hujanen (Eds.), Broadcasting and convergence: New articulations of the public service remit (pp. 123-165). Göteborg: Nordicom.

Van Kersbergen, K. and van Waarden, F. (2001). Shifts in governance: Problems of legitimacy and accountability. The Hague: MAGW Social Science Research Council.

Ward, D. (2003). State aid or band aid? An evaluation of the European Commission's approach to public service broadcasting. Media, Culture and Society, 25(3), $233-250$. 